\title{
Molecular Switches Containing Transition Metals
}

\author{
Vincent Adamo* and Peter Belser
}

\begin{abstract}
The synthesis and the characterization of a novel dithienylethene-based molecular switch bearing metal complexes are described.
\end{abstract}

Keywords: Bridging ligand · Molecular device $\cdot$ Molecular switch · Photochromism · Ruthenium complex

\section{Introduction}

The aim of miniaturization in nanotechnology has led over the last few years to a huge improvement in the knowledge of organic photochromic systems [1]. In general, photochromic molecules have been widely studied in order to develop new molecular devices able to use optical recording/reading procedures. These laser-based techniques applied to photochromic switches could reduce the memory spot size even to something as small as half of the wavelength of the incoming light. The applicability of organic photochromic molecules is restricted to a certain kind of structure. They must fulfill the following basic properties: Thermal stability of both bistable isomers, fast response, and low fatigue resistance. Among

${ }^{\star}$ Correspondence: V. Adamo

Department of Chemistry

University of Fribourg

Pérolles

$\mathrm{CH}-1700$ Fribourg

Tel.: +41263008733

Fax: +41263009738

E-Mail: vincent.adamo@unifr.ch the different types of systems employed so far, dithienylethenes containing a perfluorocyclopentene moiety integrated in the structure, have been proved to display excellent photochromic properties and low photofatigue. Nevertheless, a major problem can arise from read-out instability since the irradiation needed for the memory process can interact with the switch itself and therefore alter the initial situation. Possible solutions have been attempted but further improvement is still required. One possibility could be the introduction of metallic centers like ruthenium or osmium. The presence of these centers could allow, in the first instance, a sensitized performance of the switching unit by energy transfer after metal-based MLCT irradiation. This new approach could shift the irradiation wavelength from the UV to the visible and this would improve photofatigue. Moreover, the presence of a strong emitting metallic center like $\mathrm{Ru}(\mathrm{bpy})_{3}{ }^{2+}$ could provide a way to achieve non-destructive read-out. The emission could be tuned by the different states of the switching unit.

Different research groups have attempted the introduction of metallic centers attached to the dithienylethene unit. For instance, Launay and co-workers [2] have reported a bimetallic system where the switching unit has been symmetrically functionalized by two cyclometallated ruthenium complexes using acetylene groups as spacers. In this case a photostationary state of $75 \%$ has been achieved after irradiation at $254 \mathrm{~nm}$. Lehn and co-workers [3] reported in 1999 a system where different transition metals like tungsten, rhenium, and ruthenium were attached. Light-triggered fluorescence was achieved when metals like W or Re were used. On the other hand, the inclusion of ruthenium led to a different situation in which the photochromism of the system was blocked. The blockage acted as a chemical lock of the information and therefore data storage devices could be envisioned.

The present communication shows the synthesis of a thiophene-based diarylethene unit, covalently linked to bipyridine moieties through phenylene spacers (Schemes 1 and 2). This basic framework has been used as a ditopic ligand for the preparation of the homodinuclear metal complex with ruthenium as the metal center. The preliminary properties showed the possibility of full opening/closing cycles of the switching part in any structures reported herein, either by direct irradiation of the switching unit itself or by irradiation into the MLCT band of the covalently bonded ruthenium complex. Moreover, the presence of an emitting co-ordination center could lead to lighttriggered fluorescence behavior depending on the state of the switching unit.

\section{Preparation of the Free Ligand and the Corresponding Metal Complex}

\subsection{Ligand LSL}

The synthesis of the ligand $\mathbf{1}$ (Scheme 1) was performed first by bromination of 2-methylthiophene followed by treatment with n-butyllithium/triisopropylborate leading to 3-bromo-2-methyl-5-thiopheneboronic acid. The 4-( $p$-bromophenyl)-2,2'-bipyridine was obtained by a condensation reaction from the corresponding 'Kröhnke salt' [4] and 4-bromo-(3-carboxyl-3-oxoprop- 
1-enyl)benzene. A palladium(o) catalyzed Suzuki cross-coupling reaction between the two precursors gives the desired 3-bromothiophene derivative $\mathbf{1}$.

Treatment of $\mathbf{1}$ with n-butyllithium followed by addition of perfluorocyclopentene leads to the expected ligand 2 (LSL) (Scheme 2).

\subsection{Preparation of the Dinuclear Ruthenium Complex}

A bis-metallation reaction using $\mathrm{Ru}$ (bpy) $\mathrm{Cl}_{2}$ as precursor and the ligand $\mathbf{2}$ gives the homodinuclear metal complex [5]. Heating the reactants in 2-methoxyethanol at $120^{\circ} \mathrm{C}$ leads after an ion exchange and different purification steps to the desired compound 3 ([(bpy) $\left.\left.)_{2} \mathrm{Ru}-\mathrm{LSL}-\mathrm{Ru}(\mathrm{bpy})_{2}\right]\left(\mathrm{PF}_{6}\right)_{4}\right)$.

\section{Photophysical Properties}

\subsection{General Remarks Concerning the Photochromism}

Upon irradiation with UV-light the molecular switch in the 'open form' undergoes a light driven cyclization process to the 'closed form'. Irradiation into the absorption band lying at about $600 \mathrm{~nm}$ gives rise to a ring opening process (Scheme 3 ).
Measuring either the UV-vis spectra or the corresponding ${ }^{1} \mathrm{H}-\mathrm{NMR}$ spectra indicates clearly the evolution of the closing or opening process. The Table shows the chemical shifts of the methyl and the thiophene protons, respectively, in the open and closed form of the switching unit in $\mathbf{2}$ and $\mathbf{3}$. Furthermore, the $\lambda_{\text {max }}$ and $\varepsilon$-values of the absorption bands are also given.

The efficiency of the photochemicalinduced ring closing process is very high. For the compounds 2 (LSL) and $\mathbf{3}$ we found photostationary states of $98 \%$ and $96 \%$, respectively. Such high values for photostationary states on metal complex containing

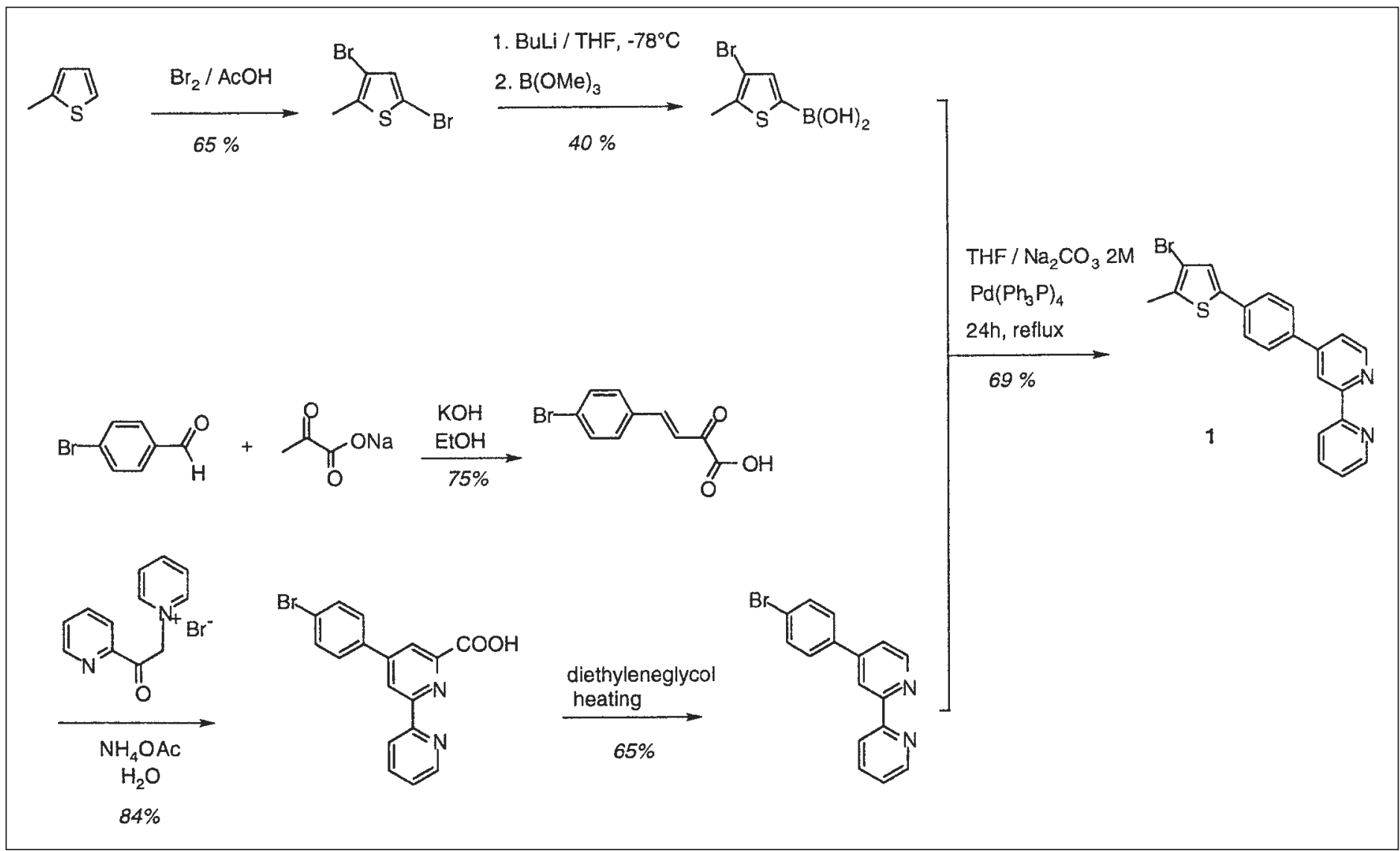

Scheme 1. Synthesis of the precursor compound 1<smiles>Cc1sc(-c2ccc(-c3ccnc(-c4ccccn4)c3)cc2)cc1Br</smiles>

1

1. BuLi / THF / $-78^{\circ} \mathrm{C}$<smiles>Cc1sc(-c2ccc(-c3ccnc(-c4ccccn4)c3)cc2)cc1C1=C(c2cc(-c3ccnc(-c4ccccn4)c3)sc2C)C(F)(F)C(F)(F)C1(F)F</smiles>

$L=$ ligand

$S$ = switching unit 


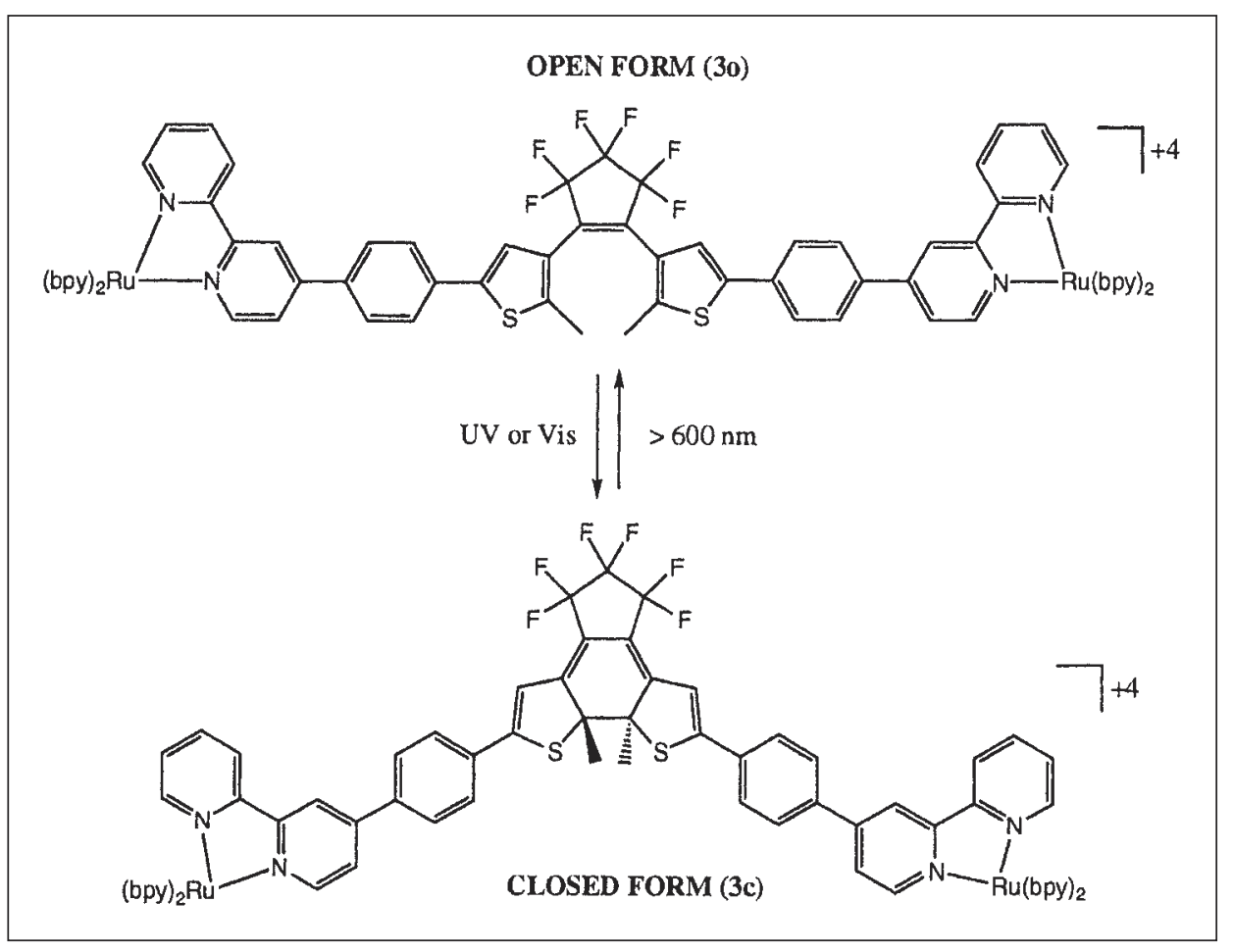

Table. ${ }^{1} \mathrm{H}$ NMR chemical shifts of selected protons and extinction coefficients for the bridging ligand 2 (LSL) and the metal complex 3 (Ru-LSL-Ru).

\begin{tabular}{|c|c|c|c|}
\hline $\begin{array}{l}\text { Compound } \\
\text { o (open); c (closed) }\end{array}$ & $\begin{array}{l}{ }^{1} \mathrm{H} \text { NMR } \\
\mathrm{Me}\end{array}$ & thiophene & $\begin{array}{l}\text { UV/Vis } \\
\lambda_{\max }[\mathrm{nm}]\left(\varepsilon \times 10^{-3} / \mathrm{cm}^{-1} \mathrm{M}^{-1}\right)\end{array}$ \\
\hline $\begin{array}{l}2 \text { o } \text { (LSL) }^{\mathrm{a}} \\
2 \text { c (LSL) } \\
3 \text { o }(\mathrm{Ru}-\mathrm{LSL}-\mathrm{Ru})^{\mathrm{b}} \\
3 \text { c (Ru-LSL-Ru) }\end{array}$ & $\begin{array}{l}2.02 \\
2.22 \\
2.09 \\
2.26\end{array}$ & $\begin{array}{l}7.35 \\
6.77 \\
7.52 \\
6.99\end{array}$ & $\begin{array}{l}322(40) \\
331(33), 603(14) \\
289(139) \\
289(132), 617(32)\end{array}$ \\
\hline
\end{tabular}

switching molecules can be explained by a nearby complete separation of the absorption bands, which are well suited for photochemical reactions [6].

\subsection{Photochromism of the Dinuclear Metal Complex}

The absorption spectrum (Fig.) shows a broad band centered at $610 \mathrm{~nm}$ corresponding to the closed isomer of the ruthenium complex. The ring opening process is achieved by irradiation into the $600 \mathrm{~nm}$ band. The closing/opening process could be repeated at least 10 times without chemical decomposition. In the case of the dinuclear ruthenium complex, a very efficient ring closing process $(\phi=0.93)$ takes place, either by direct irradiation of the switching unit with UV-light or by triplet sensitization of the ruthenium complex by irradiation into the MLCT band at $450 \mathrm{~nm}$ and subsequent energy transfer process from the excited metal center to the switching unit. A strong argument for the high quantum yield of the closing process can be given by the large peripheral groups attached to the switching unit. In fact, the dithienylethene derivative can exist in a parallel or antiparallel conformation in which only the latter is able to undergo a photocyclization process [7]. An increase of steric hindrance favors the antiparallel conformation. Indeed, the described switching unit contains bulky side groups and holds them in the preferred antiparallel conformation.

Emission spectra were measured on the metal complex $\left.\left[(\text { bpy })_{2} \text { Ru-LSL-Ru(bpy }\right)_{2}\right]^{4+}$ in the open and closed forms using an excitation wavelength of $332 \mathrm{~nm}$. Depending on the state of the switch a large discrimination in the fluorescence intensity can be observed. This different behavior in the emission properties indicates the strong influence on the energy level of the switching unit in the open and closed form, respectively. Apparently, the switching unit in the closed form represents a more conjugated molecule and has a low lying triplet energy state, which
Scheme 3. Photoconversion of the prepared metal complex. quenches drastically the excited state of the metal complex. In contrast the isomer in the open form possesses an energy level which does not perturb the emission from the ruthenium center.

\section{Conclusion}

Dithienylethene derivatives containing transition metal complexes were synthesized. A complete and reversible conversion from the open to the closed form (and vice versa) of the bistable switching molecule was observed. An incorporation of a coordination center like $\mathrm{Ru}(\mathrm{bpy})_{3}{ }^{2+}$ as sensitizer enables the use of visible light to induce a ring closure process of the switching system. The quantum yield for the photocyclization process of the compounds $\mathbf{2}$ and $\mathbf{3}$ is close to $100 \%$ probably due to the preferred antiparallel conformation adopted by the system. A pronounced discrimination of the emission intensity was observed 


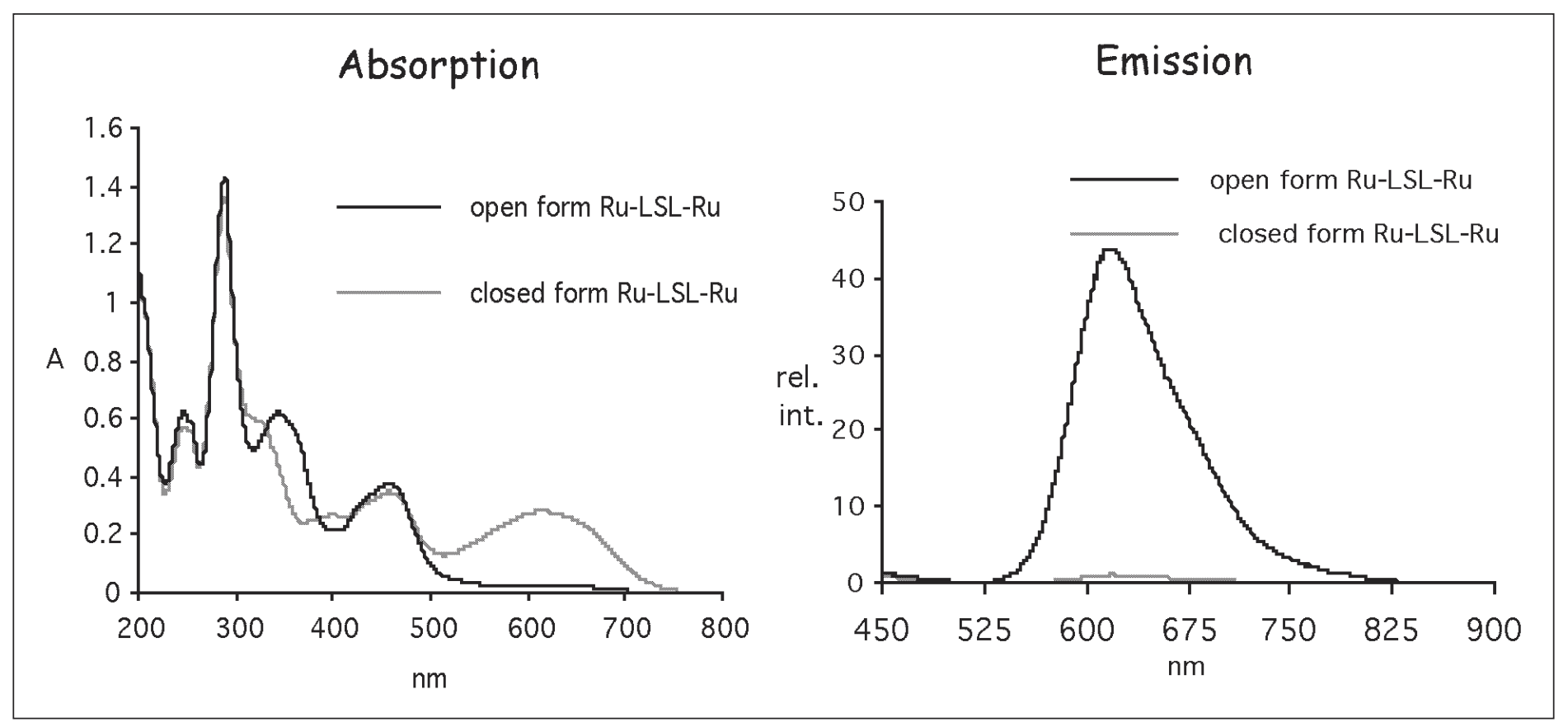

Fig. Absorption and emission spectra of the complex 3 (Ru-LSL-Ru) in a $10^{-5} \mathrm{M}$ acetonitrile solution.

depending on the open and closed form of the dithienylethene subunit in the metal complex [(bpy) $\left.)_{2} \mathrm{Ru}-\mathrm{LSL}-\mathrm{Ru}(\mathrm{bpy})_{2}\right]\left(\mathrm{PF}_{6}\right)_{4}$. Such a behavior can open interesting applications in the field of information storage.

\section{Acknowledgements}

We thank the National Swiss Science Foundation for funding through the NFP 47 program.

Received: February 7, 2003

[1] a) H. Dürr, E. Bouas-Laurent (Eds.), 'Photochromism. Molecules and Systems', Elsevier, Amsterdam, 1990; b) Special Issue on 'Molecular Materials in Electronic and Optoelectronic Devices', Acc. Chem. Res. 1999, 32; c) B.L. Feringa, W.F. Jager, B. de Lange, Tetrahedron 1993, 49, 8267.

[2] S. Fraysse, C. Coudret, J.-P. Launay, Eur. J. Inorg. Chem. 2000, 1581.

[3] a) A. Fernández-Acebes, J.-M. Lehn, Chem. Eur. J. 1999, 5, 3285; b) S.L. Gilat, S.H. Kawai, J.-M. Lehn, Chem. Eur. J. 1995, $1,275$.

[4] a) F. Kröhnke, Synthesis 1976, 1; b) M. Querol-Sans, B. Bozic, N. Salluce, P. Belser, Polyhedron 2003, accepted for publication.

[5] For synthesis of related complexes, see: a) P.A. Lay, A.M. Sargeson, H. Taube, Inorg. Synthesis 1986, 24, 292; b) A. Beyeler, P. Belser, L. De Cola, Angew. Chem., Int. Ed. Engl. 1997, 36, 2779; c) L. De Cola, V. Balzani, F. Barigelletti, L. Flamigni, P. Belser, S. Bernhard, Recl. Trav. Chim. Pays-Bas 1995, 114, 534.

[6] H.R. Schmehl, R.A. Kipp, W.Y. Kim, S. Wadhwa, M. Montalti, Inorg. Chem. 2000, 39, 76 .
[7] a) K. Shibata, K. Muto, S. Kobatake, M. Irie, J. Phys. Chem. A 2002, 106, 209; b) T. Kaieda, S. Kobatake, H. Miyasaka, M. Murakami, N. Iwai, Y. Nagata, A. Itaya, M. Irie, J. Am. Chem. Soc. 2002, 124, 2015. 